\title{
Metabolic Syndrome and Insulin Resistance Are Associated with Chronic Kidney Disease in Nondiabetic Adults with Abdominal Obesity
}

\author{
Luis Vigil $^{1}$, Albert Goday ${ }^{2}$, Rafael Gabriel ${ }^{3}$, Juan Francisco Ascaso ${ }^{4}$, Josep Franch ${ }^{5}$, \\ Rafael Ortega $^{6}$, On Behalf of the DESIRE ${ }^{*}$ Investigators
}

\begin{abstract}
${ }^{1}$ Internal Medicine, Hospital Universitario de Móstoles, Madrid, Spain; ${ }^{2}$ Endocrinology Department, Hospital del Mar, Barcelona, Spain; ${ }^{3}$ Investigation Unit, Hospital La Paz, Madrid, Spain; ${ }^{4}$ Endocrinology Department, Hospital Clínico-Universitario de Valencia, Valencia, Spain; ${ }^{5}$ Primary Care Centre Raval Sud, Barcelona, Spain; ${ }^{6}$ Medical Department, GlaxoSmithKline S.A, Tres Cantos, Madrid, Spain.

Email: lvigil.hmtl@salud.madrid.org
\end{abstract}

Received June $24^{\text {th }}, 2011$; revised July $30^{\text {th }}, 2011$; accepted August $20^{\text {th }}, 2011$.

\begin{abstract}
Aims: we investigate whether insulin resistance is associated with an increased prevalence for chronic kidney disease irrespective of the concurrent presence of metabolic syndrome. Methods: 1638 patients with abdominal obesity were selected. Metabolic syndrome and abdominal obesity were defined according to the International Diabetes Federation criteria. Insulin resistance was defined by Homeostasis Model Assessment Index $>$ P75. Chronic kidney disease was defined by the presence of a low estimated glomerular filtration rate $\left(<60 \mathrm{ml} / \mathrm{min} / 1.73 \mathrm{~m}^{2}\right)$ or microalbuminuria $(30$ $\mathrm{mg} / \mathrm{g}-300 \mathrm{mg} / \mathrm{g}$. albumin/creatinine ratio). Results: metabolic syndrome was present in $1030(62.9 \%)$ patients and insulin resistance in 787 (48\%). Conversely $61 \%$ of those with metabolic syndrome were insulin resistant and $79 \%$ of those with insulin resistance had metabolic syndrome. Chronic kidney disease was present in $18 \%$. In multivariate analysis, chronic kidney disease was increased in subjects with insulin resistance (odds ratio $[O R]=1.350 ;$ CI 95\%: $1.021-1.785 ; p=0.035)$ and in those with metabolic syndrome $(O R=1.417 ; C I 95 \%$ : $1.045-1.922 ; p=0.025)$. Conclusions: Metabolic syndrome and insulin resistance were significant and independently associated with chronic kidney disease in nondiabetic adults with abdominal obesity.
\end{abstract}

Keywords: Insulin Resistance, Metabolic Syndrome, Abdominal Obesity, Microalbuminuria, Chronic Kidney Disease

\section{Introduction}

The metabolic syndrome (MS) describes the association, in the same subject, of several traits such as central obesity, hypertension and dyslipidaemia, all of them very common conditions in developed countries. Its frequency has increased in parallel to that of global obesity and diabetes epidemic [1]. Several studies show that the presence of MS is associated to an increased risk for both cardiovascular disease [2,3] and type 2 diabetes mellitus (T2DM) [4]. In 2001 the National Cholesterol Education Program-Adult Treatment Program III (ATP-III), highlighted that the MS deserved more attention as an influence of cardiovascular (CV) risk, apart from the classical risk factors, and proposed some diagnostic criteria which could be easily used in clinical practice [5]. In April 2005, the International Diabetes Federation (IDF) published in its web page [6] a new definition of the MS based on a consensus work of a worldwide group of endocrinologists. According to this group, the reasons for a new definition that could meet with universal acceptance, in contrast to that of the ATP-III, was to allow easy identification in clinical practice, worldwide, of those individuals with the syndrome, taking into account the different ethnics. Hence, classifying a subject as having MS would require the presence of central obesity (with different cut-off points depending on the country and ethnic group) in addition to two other criteria, the same as those of the ATP-III. The importance of the MS as a chronic cardiovascular risk factor and the role of insulin resistance (IR) as its principal underlying cause have been under discussion recently [7].

The presence of chronic kidney disease (CKD) is an 
independent predictor of future $\mathrm{CV}$ events [8-11] and in the last years several studies have demonstrated that the MS increases the risk of developing microalbuminuria and renal failure [12-20]. However, just a few studies use the new proposed IDF criteria with different results with respect their association with CKD or microalbuminuria $[15,18]$. Furthermore, they do not include IR in their analysis. Insulin resistance and concomitant hyperinsulinemia are presented in CKD patients in nondiabetic US adults [21]. The present work was directed to analyse the information of an observational Spanish study in adult population (DESIRE study) [22] in order to investigate the association of insulin resistance with the risk of chronic kidney disease (CKD) in a non diabetic population. Our main objective was to study if IR is associated with the presence of CKD irrespective of whether there is concurrent MS or not.

\section{Subjects, Materials and Methods}

This is a sub analysis of the DESIRE study [22], a prospective observational cohort study involving 280 physicians (including Primary Care and Endocrinologists) and 2341 subjects $\geq 45$ years identified through primary care centres in Spain. The main objective of the DESIRE study was to assess the frequency of the metabolic syndrome and insulin resistance in an adult population assigned to Primary Care centres. From the initial sample of 2341 subjects selected, 211 did not have the inclusion criteria (abdominal obesity by IDF criteria for European population and basal plasma glucose $>90 \mathrm{mg} / \mathrm{dl}$ ). We chose the IDF definition of MS, instead of that of the ATP-III because the IDF abdominal perimeter cut-off point was one of the selection criteria used in the DESIRE study. In addition, as the IDF has included abdominal obesity as a mandatory criterion for MS, it turns out to be more in consonance with our objective, as it is, among the MS components, the most frequently related with IR [23]. In this sub analysis, within the resting 2130 group, patients with a previous diagnosis of T2DM (492, $23 \%$ ) were excluded and finally we selected 1638 subjects who met the mandatory inclusion criterion of waist circumference $\geq 94 \mathrm{~cm}$. in males and $\geq 80 \mathrm{~cm}$. in women for the diagnosis of MS according to the IDF for European population [6] (Table 1). These nondiabetics patients with abdominal obesity were referred to hospital for metabolic disorders detection (MS and/or IR) In addition to the waist circumference, diagnosis of MS required the presence of at least two of the following diagnostic criteria: triglyceride fasting level $\geq 150 \mathrm{mg} / \mathrm{dl}$, HDLcholesterol $<40 \mathrm{mg} / \mathrm{dl}$ in males and $<50 \mathrm{mg} / \mathrm{dl}$ in females, fasting plasma glucose $\geq 100 \mathrm{mg} / \mathrm{dl}$, systolic blood pressure $\geq 130 \mathrm{~mm} \mathrm{Hg}$ or diastolic $\geq 85 \mathrm{~mm} \mathrm{Hg}$ or specific treatment for each of these conditions.

The protocol and informed consent form were reviewed and approved by the Research Ethics Committee of the Hospital General Universitario of Valencia and all subjects signed an informed consent before entering the study. Reporting of the study conforms to STROBE statement along with references to STROBE and the broader EQUATOR guidelines.

\subsection{Analytical Determinations}

A complete evaluation was made through medical history and physical examination for all subjects at inclusion. Fasting blood samples were taken from each subject and processed in a central laboratory. The biochemical parameters such as plasma glucose, HDL-cholesterol and triglycerides were determined with enzymatic colorimetric method (CHOD-PAP, Roche Diagnostics). Urinary albumin concentration was determined using the nephelometry technique (Nephelometer-BNII, Dade Behring). Insulin concentration was determined using radioimmunoassay (double antibody, LINCO). Blood pressure was measured according to the recommendations of the VII Joint National Committee (JNC-VII) [24]: after at least 5-minute rest and having avoided caffeine and smoking for at least 30 minutes prior to measurement. The waist circumference (WC) was measured at the level of the umbilical scar in upright position.

\subsection{Other Parameters}

Body mass index (BMI) was calculated using Quetelet's formula (weight $(\mathrm{Kg}) /$ height $\left(\mathrm{m}^{2}\right)$ ). HOMA (Homeostasis Model Assessment) index was calculated to determine IR using the formula: value of insulin fasting $(\mu \mathrm{U} / \mathrm{ml}) \times$ fasting glycaemia $(\mathrm{mg} / \mathrm{dl}) / 405$. We calculated the distribution of the above mentioned quantitative variable in the control group of the study (general population $\geq 45$ years) and the cut-off point to be considered insulin resistant was HOMA index $>$ P75. HOMA distribution for that population was: $\mathrm{P} 25=1.71$; $\mathrm{P} 50=2.32$; and $\mathrm{P} 75=$ 3.29. Glomerular filtration rate (GFR) was obtained by the abbreviated MDRD (Modification of Diet in Renal Disease study) equation: GFR $\left(\mathrm{ml} / \mathrm{min} / 1.73 \mathrm{~m}^{2}\right)=186.3 \times$ $(\text { serum Cr})^{-1.154} \times(\text { age })^{-0.203}(\times 0.742$ in female $)$ [25] CKD was defined as the presence of a low estimated GFR (MDRD $<60 \mathrm{ml} / \mathrm{min} / 1.73 \mathrm{~m}^{2}$ ) or albumin creatinine ratio (ACR) of $30 \mathrm{mg} / \mathrm{g}-300 \mathrm{mg} / \mathrm{g}$. Both components of the endpoint (CKD) were analysed also separately.

\subsection{Statistical Analysis}

Statistical analysis was performed with SPSS 12.0. Data on quantitative characteristics were expressed as means \pm SD. Comparisons between groups were made with the $\chi^{2}$ 
Table 1. Descriptive data $\{\mathrm{n}(\%)\}$ at baseline for study group, stratified by gender.

\begin{tabular}{|c|c|c|c|}
\hline & $\begin{array}{c}\text { STUDY } \\
\mathbf{N}=1638\end{array}$ & $\begin{array}{c}\text { MEN } \\
N=646\end{array}$ & $\begin{array}{c}\text { WOMEN } \\
\mathrm{N}=992\end{array}$ \\
\hline Age, years & $60.9(9.6)$ & $61.5(9.5)$ & $60.5(9.6)^{*}$ \\
\hline Gender, male vs. female & $646(39.4)$ & - & - \\
\hline BMI, Kg/m² & $30.4(4.3)$ & $30.1(3.5)$ & $30.6(4.7)^{*}$ \\
\hline Waist circumference, $\mathrm{cm}$. & $99.5(10.2)$ & $104.3(7.7)$ & $96.3(10.6)^{*}$ \\
\hline Waist/hip circumference & $0.92(0.1)$ & $0.98(0.05)$ & $0.89(0.1)^{*}$ \\
\hline SBP, mm Hg & $136.7(17.8)$ & $137.6(17.2)$ & $136.12(18.1)$ \\
\hline DBP, mm Hg & $81.7(10.2)$ & $82.3(10.2)$ & $81.3(10.2)^{*}$ \\
\hline HВР, \% & $655(40.0)$ & $248(38.4)$ & $40.7(41)$ \\
\hline Tobacco, \% & $272(16.6)$ & $166(25.7)$ & $106(10.7)^{*}$ \\
\hline $\mathrm{N}^{0}$ cigarettes/day & $15.0(11.0)$ & $14.9(11.4)$ & $15.2(10.3)$ \\
\hline Alcohol, \% & $280(17.1)$ & $223(34.5)$ & $57(5.7)^{*}$ \\
\hline Alcohol, g/d & $29(50)$ & $33.95(57.7)$ & $17.0(17.1)^{*}$ \\
\hline Previous cardiovascular disease & $178(10.9)$ & $93(14.4)$ & $85(8.6)^{*}$ \\
\hline Fasting glycaemia, $\mathbf{m g} / \mathbf{d l}$ & $99.5(13.4)$ & $102.2(14.2)$ & $97.7(12.5)^{*}$ \\
\hline Cholesterol, mg/dl & $207.4(34.2)$ & $201.8(35.0)$ & $211.1(33.3)^{*}$ \\
\hline HDL-Cholesterol, mg/dl & $57.5(14.2)$ & $52(12.6)$ & $61.2(15.0)^{*}$ \\
\hline Triglycerides, mg/dl & $128.1(84.3)$ & $140.3(86.3)$ & $120.1(82.0)^{*}$ \\
\hline Insulin, UI/ml & $15.7(15.5)$ & $16.2(13.6)$ & $15.4(16.5)$ \\
\hline HOMA & $3.9(4.2)$ & $4.1(3.6)$ & $3.8(4.5)$ \\
\hline IR, \% & $787(49.0)$ & $329(51.8)$ & $458(47.1)$ \\
\hline Albuminuria, mg/g Cr. & $20.0(132.5)$ & $30.2(199.9)$ & $12.4(22.5)^{*}$ \\
\hline Microalbuminuria, \% & $131(9.3)$ & $68(11.1)$ & $63(7.8)^{*}$ \\
\hline MDRD & $73.3(12.5)$ & $77.2(13.1)$ & $70.7(11.4)^{*}$ \\
\hline MDRD $<60 \%$ & $201(12.5)$ & $47(7.4)$ & $154(15.8)^{*}$ \\
\hline
\end{tabular}

Quantitative variables are expressed as mean (SD). Student t-test. Categorical variables are expressed as n (\%).Chi-square statistical test *statistically significant difference between genders $(p<0.05)$. BMI: body mass index; SBP: Systolic blood pressure; DBP: Diastolic blood pressure, HBP: High blood pressure; HOMA: homeostasis model assessment; IR: insulin resistance; MDRD: glomerular filtration rate calculated by the Modification of Diet in Renal Disease equation.

test (nominal data) or Student t test (interval data). Spearman's rank correlation was used to correlate quantitative variables and logistic regression was used for OR's calculation. The analyzed variables were MS-IDF and IR in the first model and IR with each MS factor separately in the second model, considering potential confounding variables, including sex, age and BMI. We did not perform an adjustment for race because $>99 \%$ of the included population was Caucasian. All $\mathrm{P}$ values were two sided, and differences were considered statistically significant for $p<0.05$.

\section{Results}

1638 subjects were finally included in this study. Their demographic characteristics are shown in Table 1. The average age for selected subjects was 60.9 years. Plasma fasting glycaemia was $99.5 \mathrm{mg} / \mathrm{dl} .10 .9 \%$ of subjects had a previous cardiovascular event. $9.3 \%$ had microalbuminuria, $12.5 \%$ GFR $<60 \mathrm{ml} / \mathrm{min} / 1.73 \mathrm{~m}^{2}$ and $18.8 \%$ either one of these two renal injury markers. Table 1 also shows the main characteristics distributed by gender, with no significant differences observed in fasting insulin, HOMA index or IR prevalence, though women showed a higher BMI. Males presented a significantly higher prevalence of smoking habit and alcohol intake, previous cardiovascular events and microalbuminuria and less proportion of low estimated GFR.

In Spearman's bivariate correlation analysis between 
HOMA index and variables associated to the definition of MS, all the calculated coefficients were statistically significant, in the sample as a whole and when stratified by gender (Table 2 ).

$1030(62.9 \%)$ of the selected subjects presented MS and $787(48 \%)$ IR. Table 3 shows the classification of patients according to the presence or not of IR and MS and the defining characteristics of MS (excluding waist circumference, as this was an inclusion criterion) and of CKD for each group. All variables showed significant differences when assessed according to the presence of MS. When assessed according to the presence of IR all the variables showed as well significant differences between groups with the exception of an MDRD $<60 \mathrm{ml} /$ $\min$.

IR was present in $61 \%$ of patients with MS, and $79 \%$ of patients presenting IR had MS. In contrast, $48.5 \%$ of patients without IR had MS and $28.1 \%$ of subjects without MS had IR.

We performed a logistic regression analysis in order to find out which variables (MS and each of its components and IR, considered as independent categorical variables) could predict CKD and its components separately among the 1638 selected subjects. All models were adjusted for age, gender and BMI. The results are shown in Table 4. Presence of IR was associated with an increased risk of low estimated GFR (OR 1.5). However, MS (OR 1.3) did not show statistical significance with this parameter. When every component of MS was introduced separately in the model only triglyceride concentration persisted as a predictor for reduced GFR. Neither IR nor MS were predictors for microalbuminuria and only the presence of hypertension was very strongly associated with it, with almost three-time higher risk (OR 2.90). When assessing the presence of either one of the two diagnostic criteria for CKD, both IR and the MS were significantly associated, and again the level of triglycerides and hypertension persisted as independent predictors.

\section{Discussion}

In our sample, with subjects selected according to the abdominal obesity criterion of the IDF for European population, almost half of the group (48\%) had IR and

Table 2. Spearman's correlation coefficients between HOMA index and each independent factor of Metabolic Syndrome.

\begin{tabular}{lccc}
\hline & Total & Men & Women \\
\hline Fasting glycaemia & 0.48 & 0.44 & 0.53 \\
Triglycerides & 0.35 & 0.30 & 0.37 \\
HDL-Cholesterol & -0.27 & -0.25 & -0.26 \\
Insulin & 0.97 & 0.97 & 0.97 \\
Waist perimeter & 0.32 & 0.31 & 0.32 \\
SBP & 0.17 & 0.18 & 0.16 \\
DBP & 0.16 & 0.18 & 0.15 \\
\hline
\end{tabular}

All the coefficients were statistically significant $(p<0.05)$. SBP: systolic blood pressure, DBP: diastolic blood pressure.

Table 3. Frequencies of metabolic alterations $\{\mathrm{n}(\%)\}$ according to the presence of IR vs. no IR and MS vs. no MS.

\begin{tabular}{|c|c|c|c|c|}
\hline & $\begin{array}{c}\text { No IR } \\
\mathrm{N}=835\end{array}$ & $\begin{array}{c}\text { IR } \\
\mathrm{N}=803\end{array}$ & $\begin{array}{c}\text { No MS } \\
N=608\end{array}$ & $\begin{array}{c}\text { MS } \\
\mathrm{N}=1030\end{array}$ \\
\hline IR & - & - & $165(28.1)$ & $622(61.0)^{* *}$ \\
\hline MS & $398(48.5)$ & $622(79.0)^{*}$ & - & - \\
\hline Glucose-IDF & $230(28.0)$ & $464(59.0)^{*}$ & $43(7.1)$ & $653(63.4)^{* *}$ \\
\hline HBP-IDF & $580(70.7)$ & $661(84.0)^{*}$ & $324(53.3)$ & $938(91.1)^{* *}$ \\
\hline HDL cholesterol-IDF & $305(37.2)$ & $400(50.8)^{*}$ & $67(11.0)$ & $650(63.1)^{* *}$ \\
\hline Triglycerides-IDF & $156(19.0)$ & $305(38.8)^{*}$ & $18(3.0)$ & $445(43.2)^{* *}$ \\
\hline MDRD $<60$ & $98(12.0)$ & $103(13.1)$ & $59(10.0)$ & $142(13.9)^{* *}$ \\
\hline Microalbuminuria >30 & $52(7.2)$ & $79(11.4)^{*}$ & $33(6.5)$ & $98(10.8)^{* *}$ \\
\hline Chronic kidney disease & $141(17.2)$ & $167(21.2)^{*}$ & $85(14.0)$ & $223(21.7)^{* *}$ \\
\hline
\end{tabular}

Prevalence for each parameter in insulin resistant patients or not and with MS or not. Chi-square test for each or Student t-test. *Statistically significant difference between IR and no IR groups $(p<0.05) ; * *$ Statistically significant difference MS and no MS groups $(p<0.05)$. IR: insulin resistance; No IR: No insulin resistance; MS: metabolic syndrome; No MS: no metabolic syndrome; HBP: High blood pressure; MDRD: glomerular filtration rate calculated by the Modification of Diet in Renal Disease equation. 
Table 4. Multivariate analysis for the two different criteria for target organ damage (renal)*.

\begin{tabular}{|c|c|c|c|c|c|c|c|c|c|}
\hline & \multicolumn{3}{|c|}{$\operatorname{MDRD}<60 \mathrm{ml} / \mathrm{min} / 1.73 \mathrm{~m}^{2}$} & \multicolumn{3}{|c|}{$A C R>30 \mathrm{mg} / \mathrm{g}$} & \multicolumn{3}{|c|}{$\begin{array}{c}\text { MDRD }<60 \mathrm{ml} / \mathrm{min} / 1.73 \mathrm{~m}^{2} \\
\text { or ACR }>30 \mathrm{mg} / \mathrm{g}\end{array}$} \\
\hline & OR & IC $95 \%$ & $p$-value & OR & IC $95 \%$ & $p$-value & OR & IC $95 \%$ & p-value \\
\hline Insulin resistance & 1.51 & $1.08-2.10$ & 0.016 & 1.38 & $0.92-2.06$ & N.S & 1.35 & $1.02-1.79$ & 0.035 \\
\hline \multirow[t]{2}{*}{ Metabolic Syndrome } & 1.37 & $0.95-1.99$ & N.S & 1.23 & $0.79-1.92$ & N.S & 1.42 & $1.05-1.92$ & 0.025 \\
\hline & \multicolumn{3}{|c|}{ MDRD $<60 \mathrm{ml} / \mathrm{min} / 1.73 \mathrm{~m}^{2}$} & \multicolumn{3}{|c|}{ ACR $>30 \mathrm{mg} / \mathrm{g}$} & \multicolumn{3}{|c|}{$\begin{array}{c}\text { MDRD }<60 \mathrm{ml} / \mathrm{min} / 1.73 \mathrm{~m}^{2} \\
\text { or ACR }>30 \mathrm{mg} / \mathrm{g}\end{array}$} \\
\hline Insulin Resistance & 1.27 & $0.89-1.82$ & N.S & 1.34 & $0.92-2.06$ & N.S & 1.25 & $0.93-1.69$ & N.S \\
\hline HBP-IDF & 1.38 & $0.86-2.22$ & N.S & 2.91 & $1.44-5.87$ & 0.003 & 1.96 & $1.32-2.90$ & 0.001 \\
\hline HDL Cholesterol-IDF & 1.14 & $0.82-1.59$ & N.S & 0.86 & $0.59-1.26$ & N.S & 1.05 & $0.80-1.38$ & N.S \\
\hline Triglycerides-IDF & 1.60 & $1.13-2.27$ & 0.009 & 1.29 & $0.86-1.94$ & N.S & 1.50 & $1.13-1.99$ & 0.006 \\
\hline Glucose-IDF & 1.21 & $0.86-1.72$ & N.S & 0.98 & $0.66-1.45$ & N.S & 1.19 & $0.84-1.58$ & N.S \\
\hline
\end{tabular}

*Logistic regression models adjusted by gender. Age and BMI for target organ damage (renal) defined by MDRD $<60$. Microalbuminuria $>30$ or any one of them. In the first model insulin resistance and metabolic syndrome are included; the second analysis includes insulin resistance and each component of metabolic syndrome separately. MDRD: glomerular filtration rate calculated by the Modification of Diet in Renal Disease equation; ACR: albumin/creatinine ratio; HBP: High blood pressure; N.S: not significant.

$63 \%$ MS (with at least 2 more IDF criteria). This confirms the importance of abdominal obesity (even when defined by a cut-off point $8 \mathrm{~cm}$ lower than that of the ATP-III criteria) in the screening of subjects with high CVR profiles. Nevertheless, the mean WC $(104 \mathrm{~cm}$ in men and $96 \mathrm{~cm}$ in women) in our patients with abdominal obesity was higher than the ATP-III cut-off point (102 $\mathrm{cm}$ and $88 \mathrm{~cm}$ respectively). We should emphasize that among the MS components only the triglycerides persisted as an independent variable associated with the presence of abdominal obesity (in addition to BMI, age and gender).

A high percentage (79\%) of our patients with IR had MS as well, but only $61 \%$ with MS proved to be insulin resistant. These findings differ from other studies in which authors find a higher proportion of IR in patients with MS and a lower incidence of MS in the subjects with IR [26-28]. The explanation proposed for this observation is that having the glucose criteria selects a higher proportion of IR in the group of patients with MS. In our population only $63.4 \%$ of the subjects with MS had plasma glucose levels $>100 \mathrm{mg} / \mathrm{dl}$ (Table 3), whilst the most frequently observed criterion was the presence of hypertension $(91 \%)$. In addition the mean glycaemia in the study group as a whole was $<100 \mathrm{mg} / \mathrm{dl}$. These disagreements, in any case, have been part of the background for the criticism raised by the American Diabetes association (ADA) [7] indicating that MS does not reflect the presence of a single pathophysiological substrate (IR), but rather that its origin might be based in a variety of reasons. Thus, the magnitude of concordance between MS and IR would change according to the analysed populations and the MS criteria present in those. Nevertheless, on the basis of published evidence, it is reasonable to think that IR is a major cause of MS [29]. Since IR represents an independent CVR [30-32] its presence in subjects without MS would result in not detecting a significant percentage (28\%) of subjects at risk (if we only consider MS when screening). The presence of central obesity, even when defined by stricter criteria, continues selecting a population with increased CV risk, even in the absence of MS. In these subjects the determination of IR can contribute to a better detection of the above mentioned risk.

Of the two parameters used to define CKD, only the presence of a low GFR was associated to IR. It did not show statistically significant association with MS. Microalbuminuria was not associated with either IR or MS. In previous studies both microalbuminuria and low GFR were associated with the MS [12-20], although the relation of MS with microalbuminuria has been better established, appearing as a diagnostic criterion in the definition proposed by the World Health Organization (WHO) [33]. The observed discordance in our population could be due to the fact that all our subjects had by definition at least one MS diagnostic criterion (abdominal obesity), thus minimising the possible differences in the prevalence of microalbuminuria when they were classified 
according to the presence or absence of MS. Another reason might be that the majority of the studies mentioned that found a relationship with microalbuminuria used the ATP-III criteria for the diagnosis of MS. Nevertheless, Zhang et al. [15] found an association of MS (defined with IDF criteria) with both microalbuminuria and reduced GFR in the Chinese population. In contrast to this, Kitiyakara et al. [18], in a study performed in Thailand did not find an association between MS (defined by IDF) and the presence of renal insufficiency (estimated GFR $<60 \mathrm{ml} / \mathrm{min} / 1.73 \mathrm{~m}^{2}$ ), but found an association with MS when defined with the ATP-III criteria. These authors did not report about microalbuminuria.

The hyperglycaemia criterion was not associated, in our sample, with microalbuminuria, unlike in the Palaniappan study [13], though the cut-off point for glycaemia in that study was higher $(110 \mathrm{mg} / \mathrm{dl})$. Nevertheless, in the model which included IR and each of the MS components, hypertension was the strongest associated factor with microalbuminuria, as in other published studies [12], thus confirming the importance of hypertension in its development. In clinical practice, the presence of microalbuminuria can be an indicator of early vascular complications of hypertension [34,35].

In our population, hyper-triglyceridemia was the only factor associated independently with the presence of a low GFR. Several authors have investigated the association between IR and renal damage [12,36]. Palaniappan and cols. [13] reported that IR calculated by the HOMA index is associated with an increased risk of chronic renal disease in the non-diabetic population of the NHANESIII. A few epidemiological studies have shown that low concentration of HDL-cholesterol or increased triglycerides are related to an increased risk of renal failure [37]. Muntner and cols. [38] found that an increased triglyceride concentration and a low HDL-cholesterol predicted a higher risk of renal failure in more than 12000 participants in the Atherosclerosis Risk in Communities Study. A meta-analysis of clinical trials indicates that the reduction of lipid levels preserves renal function in patients with renal insufficiency [39].

These results highlight the usefulness in clinical practice of considering parameters that are easy to obtain, as the measurement of abdominal circumference and the evaluation of MS. The presence of MS was associated with CKD with even higher OR than IR. Therefore, in the presence of MS the measurement of IR would not add information in the determination of the prevalence of CKD. It is necessary to emphasize that, in our population, among the components of MS (apart from abdominal obesity) only hypertension and triglyceride levels persisted as significant markers of presence of $\mathrm{CKD}$, as pre- viously reported by other authors [40]

Chen and cols [21] identified in NHANES III population, a strong, positive, significant, and dose-response relationship among insulin resistance, insulin level, and risk of CKD among nondiabetic participants. This relationship was independent of age, gender, race, and other potential risk factors for CKD. However, as pointed out the authors, causality can not be inferred in their transversal study. At this respect, in a recently published study, in adult population in Denmark, Jeppesen et al. [41] report that IR determined using HOMA index and MS using ATP-III criteria were independent predictors for cardiovascular events after nine years of follow-up. Nevertheless MS (using IDF criteria), did not predict the development of such events. This disagreement regarding the clinical usefulness of MS (defined by IDF criteria) corrected for IR, as a marker for cardiovascular risk, can be due to the use of different methodology. Our analysis is a transversal observational study and we use renal injury markers as cardiovascular risk measurements and a direct cause-effect relationship cannot be inferred.

Our study has several limitations. One is the selection of the sample, as this is a sub-analysis which may not be representative of all the patients with MS using IDF diagnostic criteria, because we excluded from the sample individuals who met this criterion of waist circumference but had glycaemia $<90 \mathrm{mg} / \mathrm{dl}$ (in the DESIRE study the inclusion criteria were waist circumference according to IDF classification but glycaemia $>90 \mathrm{mg} / \mathrm{dl}$ ). Nevertheless it seems unlikely that a significant percentage of these patients had MS. Second, as indicated above, this is a transversal observational study and therefore we cannot establish a direct cause-effect relationship, but rather only infer the association between the presence of MS and/or IR and CKD. So, our findings do not allow one to determine whether insulin resistance contribute to the initiation or progression of $\mathrm{CKD}$, whether impaired renal function contributes to the development of insulin resistance, or whether insulin resistance is merely a marker for other causes of CKD. This nevertheless does not invalidate our study objective which was to analyze the relation of MS with IR and the contribution of these evaluations in the presence of abdominal obesity. Finally, we have used an indirect measure for IR (HOMA index), given the unfeasibility of other techniques (e.g. euglycemic clamp) in a sample of this size.

In conclusion, diagnosis of MS defined by IDF criteria is very frequent in the adult population with abdominal obesity. IR turns out to be also very prevalent in this population, though not showing a high concordance with the presence of MS. The determination of IR itself does not add any information value for the presence of CKD 
in patients with MS but may contribute to its detection in patients with abdominal obesity without metabolic syndrome.

Hypertension was the main factor associated with the presence of microalbuminuria and hyper-triglyceridemia was the main one for a decreased GFR in our population.

\section{Acknowledgements}

With the support of Glaxo-Smith-Kline SA, Tres Cantos, Madrid, Spain.

Disclosure: R. Ortega works on the Medical Department, GlaxoSmithKline S.A, Tres Cantos, Madrid.

\section{REFERENCES}

[1] P. Zimmet, K. G. Alberti and J. Shaw, "Global and Societal Implications of the Diabetes Epidemic," Nature, Vol. 414, No. 6865, 2001, pp. 782-787.

[2] H. M. Lakka, D. E. Laaksonen, T. A. Lakka, L. K. Niskanen, E. Kumpusalo and J. Tuomilehto, "The Metabolic Syndrome and Total and Cardiovascular Disease Mortality in Middle-Aged Men," Journal of the American Medical Association, Vol. 288, No. 21, 2002, pp. 27092716.

[3] C. J. Girman, T. Rhodes, M. Mercuri, K. Pyorala, J. Kjekshus and T. R. Pedersen, "The Metabolic Syndrome and Risk of Major Coronary Events in the Scandinavian Simvastatin Survival Study (4S) and the Air Force/Texas Coronary Atherosclerosis Prevention Study (AFCAPS/ TexCAPS)," The American Journal of Cardiology, Vol. 93, No. 2, 2004, pp. 136-141. doi:10.1016/j.amjcard.2003.09.028

[4] A. J. Hanley, A. Festa, R. B. D'Agostino, J. L. E. Wagenknecht, P. J. Savage and R. P. Tracy, "Metabolic and Inflammation Variable Clusters and Prediction of Type 2 Diabetes: Factor Analysis Using Directly Measured Insulin Sensitivity," Diabetes, Vol. 53, No. 7, 2004, pp. 1773-1781.

[5] Expert Panel on Detection, Evaluation, and Treatment of High Blood Cholesterol in Adults, "Executive Summary of the Third Report of the National Cholesterol Education Program (NCEP) Expert Panel on Detection, Evaluation, and Treatment of High Blood Cholesterol in Adults (Adult Treatment Panel III)," Journal of the American Medical Association, Vol. 285, No. 19, 2001, pp. 24862497.

[6] International Diabetes Federation, "The IDF Consensus Worldwide Definition of the Metabolic Syndrome," 2009. www.idf.org/webcast/pdf/IDF.

[7] R. Kahn, J. Buse, E. Ferrannini and M. Stern, "The Metabolic Syndrome: Time for a Critical Appraisal: Joint Statement from the American Diabetes Association and the European Association for the Study of Diabetes," Diabetes Care, Vol. 28, No. 9, 2005, pp. 2289-2304. doi:10.2337/diacare.28.9.2289

[8] M. J. Sarnak, A. S. Levey, A. C. Schoolwerth, J. Coresh,
B. Culleton and L. L. Hamm, "Kidney Disease as a Risk Factor for Development of Cardiovascular Disease: A Statement from the American Heart Association Councils on Kidney in Cardiovascular Disease, High Blood Pressure Research, Clinical Cardiology, and Epidemiology and Prevention," Circulation, Vol. 108, 2003, pp. 21542169.

[9] H. C. Gerstein, J. F. Mann, Q. Yi, B. Zinman, S. F. Dinneen and B. Hoogwerf, "Albuminuria and Risk of Cardiovascular Events, Death, and Heart Failure in Diabetic and Nondiabetic Individuals," Journal of the American Medical Association, Vol. 286, No. 4, 2001, pp. 421-426.

[10] K. Wachtell, H. Ibsen, M. H. Olsen, K. Borch-Johnsen, L. H. Lindholm and C. E. Mogensen, "Albuminuria and Cardiovascular Risk in Hypertensive Patients with Left Ventricular Hypertrophy, the LIFE Study," Annals of Internal Medicine, Vol. 139, No. 11, 2003, pp. 901-906.

[11] H. L. Hillege, V. Fidler, G. F. Diercks, W. H. van Gilst, D. de Zeeuw and D. J. van Veldhuisen, "Urinary Albumin Excretion Predicts Cardiovascular and Noncardiovascular Mortality in General Population," Circulation, Vol. 106, No. 14, 2002, pp. 1777-1782.

[12] J. Chen, P. Muntner, L. L. Hamm, D. W. Jones, V. Batuman, V. Fonseca and Whelton, "The Metabolic Syndrome and Chronic Kidney Disease in U.S. Adults," Annals of Internal Medicine, Vol. 140, No. 3, 2004, pp. 167-174.

[13] L. Palaniappan, M. Carnethon and S. P. Fortmann, "Association between Microalbuminuria and the Metabolic Syndrome: NHANES III," American Journal of Hypertension, Vol. 16, No. 11, 2003, pp. 952-958. doi:10.1016/S0895-7061(03)01009-4

[14] M. Kurella, J. C. Lo and G. M. Chertow, "Metabolic Syndrome and the Risk for Chronic Kidney Disease among Nondiabetic Adults," Journal of the American Society of Nephrology, Vol. 16, No. 7, 2005, pp. 2134-2140. doi:10.1681/ASN.2005010106

[15] L. Zhang, L. Zuo, F. Wang, M. Wang, S. Wang and L. Liu, "Metabolic Syndrome and Chronic Kidney Disease in a Chinese Population Aged 40 Years and Older," Mayo Clinic Proceedings, Vol. 82, No. 7, 2007, pp. 822-827. doi:10.4065/82.7.822

[16] T. Ninomiya, Y. Kiyohara, M. Kubo, K. Yonemoto, Y. Tanizaki and Y. Doi, "Metabolic Syndrome and CKD in a General Japanese Population: The Hisayama Study," American Journal of Kidney Diseases, Vol. 48, No. 3, 2006, pp. 383-391. doi:10.1053/j.ajkd.2006.06.003

[17] M. Tozawa, C. Iseki, K. Tokashiki, S. Chinen, K. Kohagura and K. Kinjo, "Metabolic Syndrome and Risk of Developing Chronic Kidney Disease in Japanese Adults," Hypertension Research, Vol. 30, No. 10, 2007, pp. 937943. doi:10.1291/hypres.30.937

[18] C. Kitiyakara, S. Yamwong, S. Cheepudomwit, S. Domrongkitchaiporn, N. Unkurapinun and V. Pakpeankitvatana, "The Metabolic Syndrome and Chronic Kidney Disease in a Southeast Asian Cohort," Kidney International, Vol. 71, No. 7, 2007, pp. 693-700. 


\section{doi:10.1038/sj.ki.5002128}

[19] J. E. Lee, S. Y. Choi, W. Huh, Y. G. Kim, D. J. Kim and H. Y. Oh, "Metabolic Syndrome, C-Reactive Protein, and Chronic Kidney Disease in Nondiabetic, Nonhypertensive Adults," American Journal of Hypertension, Vol. 20, No. 6, 2007, pp. 1189-1194.

[20] J. Lucove, S. Vupputuri, G. Heiss, K. North and M. Russell, "Metabolic Syndrome and the Development of CKD in American Indians: The Strong Heart Study," American Journal of Kidney Diseases, Vol. 51, No. 1, 2008, pp. 21-28. doi:10.1053/j.ajkd.2007.09.014

[21] J. Chen, P. Muntner, L. L. Hamm, V. Fonseca, V. Batuman and P. K. Whelton, "Insulin Resistance and Risk of Chronic Kidney Disease in Nondiabetic US Adults," Journal of the American Society of Nephrology, Vol. 14, No. 2, 2003, pp. 469-477. doi:10.1097/01.ASN.0000046029.53933.09

[22] A. J. Goday, R. Gabriel, J. F. Ascaso and DESIRE Investigators, "Riesgo Cardiovascular en Sujetos con Alta Probabilidad de síNdrome Metabólico y Resistencia a la Insulina. Estudio DESIRE," Revista Clínica Española, Vol. 208, No. 8, 2008, pp. 377-385. doi:10.1157/13126339

[23] S. E. Stern, K. Williams, E. Ferrannini, R. A. DeFronzo, C. Bogardus and M. P. Stern, "Identification of Individuals with Insulin Resistance Using Routine Clinical Measurements," Diabetes, Vol. 54, No. 2, 2005, pp. 333339.

[24] A. V. Chobanian, G. L. Bakris, H. R. Black, W. C. Cushman, L. A. Green and J. L. Izzo Jr., "The Seventh Report of the Joint National Committee on Prevention, Detection, Evaluation, and Treatment of High Blood Pressure: The JNC 7 Report," Journal of the American Medical Association, Vol. 289, No. 19, 2003, pp. 25602572.

[25] A. S. Levey, J. Coresh, E. Balk, A. T. Kausz, A. Levin and M. W. Steffes, "National Kidney Foundation Practice Guidelines for Chronic Kidney Disease: Evaluation, Classification, and Stratification," Annals of Internal Medicine, Vol. 139, No. 2, 2003, pp. 137-147.

[26] T. McLaughlin, F. Abbasi, K. Cheal, J. Chu, C. Lamendola and G. Reaven, "Use of Metabolic Markers to Identify Overweight Individuals Who Are Insulin Resistant," Annals of Internal Medicine, Vol. 139, No. 10, 2003, pp. 802-809.

[27] Y. Liao, S. Kwon, S. Shaughnessy, P. Wallace, A. Hutto and A. J. Jenkins, "Critical Evaluation of Adult Treatment Panel III Criteria in Identifying Insulin Resistance with Dyslipidemia," Diabetes Care, Vol. 27, No. 4, 2004, pp. 978-983. doi:10.2337/diacare.27.4.978

[28] K. L. Cheal, F. Abbasi, C. Lamendola, T. McLaughlin, G. M. Reaven and E. S. Ford, "Relationship to Insulin Resistance of the Adult Treatment Panel III Diagnostic Criteria for Identification of the Metabolic Syndrome," Diabetes, Vol. 53, No. 5, 2004, pp. 1195-1200.

[29] S. M. Grundy, J. I. Cleeman, S. R. Daniels, K. A. Donato,
R. H. Eckel and B. A. Franklin, "Diagnosis and Management of the Metabolic Syndrome: An American Heart Association/National Heart, Lung, and Blood Institute Scientific Statement," Circulation, Vol. 112, No. 17, 2005, pp. 2735-2752.

[30] G. Hu, Q. Qiao, J. Tuomilehto, M. Eliasson, E. J. Feskens and K. Pyorala, "Plasma Insulin and Cardiovascular Mortality in Non-Diabetic European Men and Women: A Meta-Analysis of Data from Eleven Prospective Studies," Diabetologia, Vol. 47, No. 7, 2004, pp. 1245-1256.

[31] J. P. Despres, B. Lamarche, P. Mauriege, B. Cantin, G. R. Dagenais and S. Moorjani, "Hyperinsulinemia as an Independent Risk Factor for Ischemic Heart Disease," The New England Journal of Medicine, Vol. 334, No. 15, 1996, pp. 952-957. doi:10.1056/NEJM199604113341504

[32] M. Pyorala, H. Miettinen, P. Halonen, M. Laakso and K. Pyorala, "Insulin Resistance Syndrome Predicts the Risk of Coronary Heart Disease and Stroke in Healthy Middle-Aged Men: The 22-Year Follow-Up Results of the Helsinki Policemen Study," Arteriosclerosis, Thrombosis, and Vascular Biology, Vol. 20, No. 2, 2000, pp. 538-544. doi:10.1161/01.ATV.20.2.538

[33] K. G. Alberti and P. Z. Zimmet, "Definition, Diagnosis and Classification of Diabetes Mellitus and Its Complications, Part 1: Diagnosis and Classification of Diabetes Mellitus Provisional Report of a WHO Consultation," Diabetic Medicine, Vol. 15, No. 7, 1998, pp. 539-553. doi:10.1002/(SICI)1096-9136(199807)15:7<539::AID-DI A668>3.0.CO;2-S

[34] X. Jiang, S. R. Srinivasan, B. Radhakrishnamurthy, E. R. Dalferes Jr., W. Bao and G. S. Berenson, "Microalbuminuria in Young Adults Related to Blood Pressure in a Biracial (Black-White) Population. The Bogalusa Heart Study," American journal of hypertension, Vol. 7, No. 1, 1994, pp. 794-800.

[35] B. M. Brenner, "Hemodynamically Mediated Glomerular Injury and the Progressive Nature of Kidney Disease," Kidney International, Vol. 23, 1983, pp. 647-655. doi:10.1038/ki.1983.72

[36] C. M. Hoehner, K. J. Greenlund, S. Rith-Najarian, M. L. Casper and W. M. McClellan, "Association of the Insulin Resistance Syndrome and Microalbuminuria among Nondiabetic Native Americans, the Inter-Tribal Heart Project," American Society of Nephrology, Vol. 13, No. 6, 2002, pp. 1626-1634. doi:10.1097/01.ASN.0000015762.92814.85

[37] L. G. Hunsicker, S. Adler, A. Caggiula, B. K. England, T. Greene and J. W. Kusek, "Predictors of the Progression of Renal Disease in the Modification of Diet in Renal Disease Study," Kidney International, Vol. 51, 1997, pp. 1908-1919. doi:10.1038/ki.1997.260

[38] P. Muntner, J. Coresh, J. C. Smith, J. Eckfeldt and M. J. Klag, "Plasma Lipids and Risk of Developing Renal Dysfunction: The Atherosclerosis Risk in Communities Study," Kidney International, Vol. 58, 2000, pp. 293-301. doi:10.1046/j.1523-1755.2000.00165.x

[39] L. F. Fried, T. J. Orchard and B. L. Kasiske, "Effect of 
Lipid Reduction on the Progression of Renal Disease: A Meta-Analysis," Kidney International, Vol. 59, 2001, pp. 260-269. doi:10.1046/j.1523-1755.2001.00487.x

[40] L. Mykkanen, D. J. Zaccaro, L. E. Wagenknecht, D. C. Robbins, M. Gabriel and S. M. Haffner, "Microalbuminuria is Associated with Insulin Resistance in Nondiabetic Subjects: The Insulin Resistance Atherosclerosis Study,"
Diabetes, Vol. 47, No. 5, 1998, pp. 793-800.

[41] J. Jeppesen, T.W. Hansen, S. Rasmussen, H. Ibsen, C. Torp-Pedersen and S. Madsbad, "Insulin Resistance, the Metabolic Syndrome, and Risk of Incident Cardiovascular Disease: A Population-Based Study," Journal of the American College of Cardiology, Vol. 49, No. 21, 2007, pp. 2112-2119. doi:10.1016/j.jacc.2007.01.088 


\section{"DESIRE Investigators}

\section{Hospital Investigators}

Álava: R. Ezquerra; L. Irigoyen; F.J. Escalada; M.A. Vicente; C. Fuentes; P. Sierra. Alicante: J. Martí; R. Serra; A.I. Martí; A. Picó; A. Martín; M.I. Pérez; A. Maestre; J.R. Domínguez; F.J. Pomares. Badajoz: F.J. Morales; L.J. Fernández. Barcelona: J. Mesa; G. Francisco; E. Losada; C. Villabona; J. Mayos; A. Goday. Cáceres: L. Enríquez; E. Castro. Cádiz: M. Aguilar; B. Lahoz; M. Bejarano; A. Michán. Cantabria: J. Freijanes; R. de la Pedraja; C. Montalban; P. Abab. Ciudad Real: R. Chamorro; M. Aguirre; A. Rodríguez. Córdoba: R. Palomares; G. Manzano; J. Moreno; M.A. Gálvez. Cuenca: J. Aranda; D.M. Calderón; C. Gómez. Granada: F. Escobar; M.M. Campos; T. Muros; G. Piedrola; M. López de la Torre. Gran Canaria: P. de Pablos; I. García. Guadalajara: E. Costilla; M.D. Mateo. Guipúzcoa: M. Goena; J. Espiga. Huelva: A. Barrios; E. Haya; H. Sánchez; C. García. Jaén: A. Moreno; P. Santiago; C. Sánchez. La Coruña: A. Pose; J.M. Martínez. Lanzarote: J.C. Castro. León: I. Cano; B. Pérez; M. Ballesteros; R. Aguado. Madrid: M. Serrano; F. Perez; J.A. Sánchez; G. Martínez; F. Hawkins; L. García; J.J. Cornejo; J.R. Calle; M.P. Ruiz; P. Martín; M. Martín de Santolalla; J.L. Herrera; M.A. Gonzalo; J.I. Lara; A. Gómez; R. Carraro; M.E. Sánchez; M. Botella; P. Saavedra. Málaga: J.L. Pinzón; M.J. Picón. Mallorca: V. Pereg; C. Sáinz; H. García; M. Codina; J.R. Urgelés; I. Rodríguez; S. Tofé. Murcia: A. Hernández; G. Liante; F. Illán; S. Alcaráz; M. Pascual. Navarra: E. Menéndez; L. Forga; J. Pineda. Orense: A. Mato; I. Solache; A. Gippini; M.T. Fernández; Pontevedra: E. Pena; M.J. Morales; M.A. Martínez; V. Muñoz. Sevilla: F. Losada; F. Relimpio; A. Pumar; M.A. Mangas; A. Gentil; S. Durán; M. Sevillano. Tarragona: J.M. Manzanares. Toledo: J. López; J. Sastre; A. Vicente; A. Marco. Valencia: S. Tenés; A. Merchante; M. Civera; F.J. Ampudia; R. Lorente; F. Merino; V. Campos; A. Hernández; C. Morillas; D.M. Godoy; A. González-Cruz. Valladolid: J. Zurro; E. González; J.L. Delgado; I. Fernández. Vizcaya: J.J. Beitia; R. Arteaga; J.A. Vázquez; F. Vázquez; J.I. Goicolea; R. Elorza; A. Yoldi; C. Moreno; E. Ugarte; F. Goñi; A. Oleaga; A. Izuzquiza; M. Paja. Zaragoza: R. Albero; J. Ache; M.O. Bandrés.

\section{Primary Care Centre Investigators}

Álava: M.T. Medrano; J. Ibarra; A.I. López de Viñaspre; J. Iturralde. Alicante: R. Alarcón; C. Gisbert; J.T. Solano; M. Ruiz; J.M. Segura; S. Pertusa; J. Torregrosa; C. de la Sen; E. Cases; F. Urban; D. Vicente; J.A. Paya; E. Romero; C. López-Quintana; M. Aleo. Almería: J.J. Vaquero; J.M. Sánchez; F.J. Llave; R. Domínguez; E.
Díaz. Badajoz: A. Moreno; J.P. Almeida; M.J. Cano; C. Carrasco; R. Sánchez. Barcelona: X. Robiro; J. Alins; R. Rodó; J. Franch; B. Benito; E. Almendro; J. Verdú; M. Mata; I. Bobe; L. González; J.D. Guevara; R. Gómez. Cáceres: M. Turégano; J.M. Villanueva; F. Sanjuan; A. Barquilla; A. Fernández; S. Lupiani; V. Barchilon; M. López. Cádiz: A. Fernández; J. Escribano. Cantabria: M. Martínez; C. Aguado; V. Morago; E. Basabe; D. García; Y. Cuerno; G. Arranz. Ciudad Real: A. Ruiz; J.M. Morales; A. Álvarez. Córdoba: J.J. García; S.M. Gil; J.M. González; A. Reguillo. Cuenca: M.D Ruiz; P. Valle. Granada: V. Sánchez; N. Barchein; L. Zúñiga; J.L. Sabatel; A. Casares; J.F. Vargas. Gran Canaria: R. Monzón; A. Montesdeoca; F. Álvarez; R. García; A. Lasso; A. González. Guadalajara: M.D. Retuerta; J. Arribas; J.R. Jiménez; I. López. Guipúzcoa: J.J. Bilbao; D. Ibáñez; J.M. Echeveste; L.I. Unzueta; P. Ezcurra; B. Anzola; L. Galparsoro; J. Martiarena. Huelva: V. Regife; Y. Corchado. Jaén: R. Aguilera; M. García; M.I. Ballesta; A. Moreno; P. Ruiz. La Coruña: J.M. López; J. Pazos; N. Proupín; J.A. Ferreiro; A. Pestaña; A. Freire. Lanzarote: M.J. Sánchez; M.J. Pérez. León: J.C. Álvarez; M. Rodríguez; R. Ordoñez; M. García; J.A. Ríos; F.J. García-Norro; F. Díez; A. Lisarrague; J.M. Marcos; N. Suarez; J. Duque; J. Estopá; L.S. López; C. Neiga; A.M. Pérez. Madrid: F. Latorre; P. Jiménez; M. López; J. Arroyo; P. Matarí; M.A. Férnandez; A. Córdoba; M. Requena; M.R. Serrano; J. Castellanos; E. Olano; A. Andrino; J.J. González; S.P. Seguido; M. Martín; L. Rubiera; J. Sagredo; M. Almarza; L. García; P. Elviro; C. Rodríguez; F. Muñoz; G. Vázquez; B. Novella; J.L. Antón; J. Sanz; T. Sarriá; N. Reyes; Y. de la Fuente; F.J. Sierra; B. Sierra; L. Puertas; M. Masip; F. Imaz; A. López. Málaga: J.C. Villalobos; J.M. Ramírez. Mallorca: M. Román. Manacor: B. Barceló; N. Feuerbach; M.A. Mulet. Murcia: I. Martínez; J.F. Martínez; A. Martínez; M.J. Sánchez; J.E. Carrasco; J. Aliaga; B. Guillamón; L. García; L. Guirao; J.B. Gómez; R. López. Navarra: J. Agreda; P. Pascual; J. Ulibarri del Portillo; M.M Hernández.Orense: M. González; E. Abellas; M.J. Arias; A.J del Álamo; M.J Fernández; A. González; M.C La López; M. Muñiz; M.B. Novoa; A. Veiga; J. Lloveres; T. Marchena; C. Menéndez; M.D. Antolín; M.J. Madroño; A. Padrón; S. Rey; A. González; A. Diéguez; S. Abelleira; F.J. Jorge; M.C. Martín; A. Reinoso; R. Rulín. Pontevedra: J.M. Sáez de Biteri; T. Alonso; C. Boullón; S. Cadarso; J. Montes; A. Marino; P. Ibáñez; C. Pérez; F. Bacariza; J.B. Rodríguez; M.F. Sainz; A. Charle; F.J. García; F.J. Sanisidro; M.J. Torres. Sevilla: M. Baeza; J. Suárez-Varela; J.M. Sánchez; F. García; M. Sánchez; F. Ramírez; F.J. de Tena. Tarragona: M. Andreu; F. Sancho; X. Escoda; J. Sanmiguel; S. López. Toledo: F. Gómez; J. 
Hernández; J.M. Comas; P. Gil; C. de Castro; A. Barbado; F.J. Alonso. Valencia: S. Martínez; A. Artero; A. Brotons; S. Gras; J.M. Martínez; J.M. Pilar; V. Meneu; L. Laporta; A. Peiró; L. Estal; F. Valls; V. Valor; J.B. Seguí; C. Insausti; J.V. Climent; R.J. Fornas; T. Fuster; R. Albelda; A. Pastor; J. Gaona; J.V. Lozano; C. Arroyo; M.J. Ila; M.J. Peris; L. Vives; N. Blanes; L. Bordes; C. Pradas; A. López; A. Fortea; A. León; F. Úbeda; J. Puchol; J.M. Gil; J.A. Bonet; J. Ribelles; P. Fernández; E. Sahuquillo; M.J.
Monzó; J.J. Martínez; J.I Chirivella. Valladolid: F. Montiel; F. Olmos; E. Cotobal; B. Torrijos; J.A. García; B. González. Vizcaya: P. de la Maza; A. Serrano; J. Antón; A. Arrugaeta; L. Uribe-Etxebarria; M.M. Bilbao; J. Martínez; F. Mato; J.M. Cascán; L. Ruiz; F. Medel; A. Gangoiti; I. Beitia; L. Aurrekoetxea; G. Salaverri; B. Goiría. Zaragoza: P. Garro; A. Alfaro; F.J. Buded; M. Solano; J.J. Calvo; J.A. Esparza; M. Hernández; J. Codes; P. Abadía. 